explanation. Predictions are made during the course of analysis which may turn out to be correct or incorrect. Freud used the data gathered from his analysands to modify his original theory: he moved on from the 'affecttrauma phase' during which he studied cases of hysteria and conjectured that they were the result of affect being repressed due to a major trauma, to the 'topographical phase', in which he evolved the theory of unconscious, preconscious and consciousness, when it became apparent that his patients had rarely suffered the actual trauma (initially thought to be incest). Later he developed the theory of ego, superego and id, thus elaborating the 'topographical phase'.

Turning to Anderson's concern that psychoanalysis explains 'whatever happens'; all disciplines attempt to explain 'whatever happens' within their frame of reference. As the physical sciences attempt to explain the physical world, so psychoanalysis attempts to explain the intrapsychic world. Both have levels of explanation which can be likened to Bhaskar's 'generative mechanisms'.

Returning to an early point in my article: a Popperian cannot allow the possibility of psychoanalysis being a science: all my critics suggest that this does not matter. I disagree, since I think that it is important to transcend the limitations of Popperianism and find an adequate philosophy of science that can include psychoanalysis, because if useful research is to be done, it needs to be supported by a coherent philosophy.

St George's Hospital

Tooting, London SW17

REFERENCES

'MATHERs, Carola B. (1986) Psychoanalysis: science or nonscience? Bulletin of the Royal College of Psychiatrists, 10, 103-104.

${ }^{2}$ HARRE, R. (1972) The Philosophies of Science. Oxford University Press.

(This discussion is now closed. Eds.)

\section{A community group in the State Hospital DeAr Strs}

Dr Cantor, in his comment on Dr Novosel's paper on a Community Group in the State Hospital (Bulletin, December $1986,10,360$ ) rightly stresses the importance of being critical of "any treatment modality that is expensive in terms of staff resources". I would go further than this and stress the importance of being critical of any treatment modality, irrespective of cost. Dr Cantor goes on to criticise Dr Novosel's group, and says that he could find no evidence in the paper to support Dr Novosel's claim for the group's success.

I continue to agree with Dr Cantor that it is important to determine by what criteria success can be judged. This is the difficult part.
Unfortunately, Dr Cantor illustrates his plea for an empirical approach to assessing such groups, by giving the sort of caricature of a scientific attitude that gives statistical research a bad name. He writes that the group, if tested by a depression rating scale, would be likely to have registered "a profound increase in depressive symptoms", as if this shows the group was not successful. It seems to me that if a group of people, "the majority having a diagnosis of schizophrenia", most of whom have committed crimes, are to become depressed, this might be seen as a sign of progress and maturation. I would call this "success".

Duke Street Hospital

ROBERT WHYTE

Glasgow

\section{The Folly of Deterrence \\ A reply to Ian Deary}

Dear Sirs

Ian Deary's support for the 'Wisdom of Deterrence-a reply to Jim Dyer'1,2 combines a little psychology and a lot of political opinion on defence policy. Albert Einstein displayed greater psychological wisdom when he noted-"The unleashed power of the atom has changed everything except our way of thinking, and thus we drift towards unparalleled catastrophe. We shall require a substantially new manner of thinking if mankind is to survive". ${ }^{3}$ Deterrence is a prenuclear concept mistakenly applied to nuclear weaponry. It assumes that the threat of massive destruction will restrain the 'enemy'. If deterrence is military policy, what is the justification for the accumulation of 50,000 nuclear weapons, the equivalent of 4 tonnes of TNT for every man, woman and child on earth?

A further illusion of Dr Deary is that nuclear weapons have kept the peace between the US and USSR in the past 40 years. This is a very blinkered view of history. These two nations were allies in World War 2 and were not adversaries before the nuclear age. Dr Deary's apparent conclusion that nuclear weapons have conventional political uses is based on the premise of a limited nuclear war and not deterrence.

The World Health Organization has identified nuclear war as the greatest threat to the health and welfare of mankind, it is not just Dr Dyer's view. Palaentologists remind us that of all the species that have existed on this planet, $99 \%$ are now extinct. The nuclear syndrome may well be our Achilles heel. Nuclear war carries the threat of omnicide-extinction of the species homo sapiens, as a real possibility.

In psychological terms, nuclear weapons are the symbol of power. Britain, having lost its empire, spends enormous sums to preserve the symbol, while its National Health Service and educational system crumble and unemployment soars. To suggest that nuclear weaponry is not expensive is a fallacy. The British Trident submarine programme is costing $£ 10$ billion. One trillion dollars is the price tag of SDI (Star Wars). 